\title{
Low doses of alpha particle irradiation modify the expression of genes regulating apoptosis in human MCF-7 breast cancer cells
}

\author{
JESÚS SOTO ${ }^{1}$, CARLOS SAINZ ${ }^{1}$, DOMINGO GONZÁLEZ-LAMUÑO ${ }^{2}$ and SAMUEL COS $^{3}$ \\ Departments of ${ }^{1}$ Medical Physics, ${ }^{2}$ Genetic Pediatrics, and ${ }^{3}$ Physiology and Pharmacology, \\ School of Medicine, University of Cantabria, 39011 Santander, Spain
}

Received May 3, 2005; Accepted July 6, 2005

\begin{abstract}
The possibility of modifying apoptosis-related genes in tumor cells is an interesting line of research that calls for multidisciplinary experimentation to describe its characteristics and the conditions required. In vitro low doses of alpha particle irradiation due to radon have an antiproliferative effect on the growth of MCF-7 cells and increase the sensibility of cancer cells to taxol, a chemotherapeutic agent that induces cellular apoptosis. The present study examines the in vitro effects of low doses of alpha particle irradiation from the gas radon on the expression of some Bcl-2 family apoptosis-related genes. The analyzed genes were bax, bcl-2 and bcl-x, with known responses to genotoxic stress (bcl-2) or ionising radiation (bax and bcl-x) in MCF-7 human breast cancer cells. The results obtained indicate that the cell line studied expresses the mentioned genes and they demonstrate that irradiation with low radon doses of MCF-7 cells induces underexpression of both bax and bcl-2 genes. Interestingly, the mRNA levels of the fulllength bcl-x gene $\left(\mathrm{bcl}-\mathrm{x}_{\mathrm{L}}\right)$ were overexpressed after irradiation, and we found significant mRNA levels of an alternative mRNA splicing form of the same gene $\left(\mathrm{bcl}-\mathrm{x}_{\mathrm{S}}\right)$, which enhances the apoptotic sensitivity of the cell. The increased sensitivity to apoptosis resulting from bcl- $\mathrm{x}_{\mathrm{S}}$ overexpression is important because it might improve the efficacy of chemotherapeutic agents used to treat cancers which act through induction of apoptosis. The finding that low radiation doses of alpha particles from the gas radon modulate the expression of apoptosis-related genes suggests a therapeutic utility for this naturally occurring agent.
\end{abstract}

\section{Introduction}

The use of radiation to increase the efficacy of a chemotherapeutic agent in the treatment of cancer patients is an interesting possibility because of the need to reduce both the

Correspondence to: Dr Samuel Cos, Departamento de Fisiología y Farmacología, Facultad de Medicina, Universidad de Cantabria, Cardenal Herrera Oria s/n, 39011 Santander, Spain

E-mail: coss@unican.es

Key words: radiation, radon, MCF-7 cells, breast cancer, apoptosis action on healthy cells and the side effects $(1,2)$. The aim of this treatment modality is for the radiation to produce a sublethal effect on the cells, which makes them more sensitive to the action of the drug and thus increases its efficacy. There is evidence relating the growth of breast cancer to radiation from the radioactive gas radon $\left({ }^{222} \mathrm{Rn}\right)$. Remission of breast tumors was reported for mice receiving a low dose of radiation combined with a strict diet (3). We have previously reported that low doses of radon $\left({ }^{222} \mathrm{Rn}\right)$ dissolved in the cell culture medium have a significant antiproliferative effect on the growth of MCF-7 human breast cancer cells (4). Low doses of radon $\left(3 \times 10^{-3} \mathrm{~Gy}\right)$ also enhance the sensibility of tumor cells to the antiproliferative effect of taxol, a chemotherapeutic agent that induces cellular apoptosis (5). Although the action mechanism of alpha particles on tumor cells is not very well understood, a possible modulation of the expression of genes related to apoptosis has been suggested (5).

Apoptosis or programmed cell death is a critical component of homeostasis in organs and tissue. Different gene families regulate the characteristic sequence of events of apoptotic cell death. The Bcl-2 family of proteins plays a fundamental role in apoptotic control, several members of which appear to play important positive and negative roles in the control of apoptosis (6). The main apoptotic inhibitors are bcl-2 and $\mathrm{bcl}-\mathrm{x}_{\mathrm{L}}$, a protein product of the $\mathrm{bcl}-\mathrm{x}$ gene. Overexpression of these inhibitor members has been reported in drug resistance phenomena of several tumor types (7). On the other hand, the pro-apoptotic family members include $b c l-x_{S}$, a truncated protein encoded by the bcl-x gene, bax and bad, which has been shown to act against bcl-2 and/or bcl- $x_{L}(8,9)$.

The combined action of inductor/inhibitor genes can be influenced by external factors (10). Several chemotherapeutic drugs act through apoptosis and its mode of action can be diverse over the cell structure, increasing the expression of genes related with apoptotic pathways, such as p53 and Bcl-2 family members. Also, biological agents, such as adenovirus, have been used to increase the expression of apoptosis-inducing genes such as bcl- $\mathrm{x}_{\mathrm{S}}(11)$. In the same way, low doses of ionising radiation seem to be able to modify the expression of this kind of gene, changing the cellular sensitivity to apoptosis. Several genetic effects of ionising radiation have been reported. For low LET radiation ( $\beta, \gamma$ and $X$ radiation), changes in mRNA levels corresponding to bcl-x have been reported (10). Also, other studies have shown induction of apoptosis (12), stimulus of enzymatic repair mechanisms 
(13) and, in the high-dose range, increased mutagenesis and genomic instability (14). However, a few studies analyse this kind of effect for high LET radiation ( $\alpha$ and $n$ ). Also, for high and intermediate doses, increased mutagenesis, chromosomal alterations (15) and changes in size and structure of DNA (16) have been reported.

In the low-dose range, there is a virtual absence of studies on the effects of alpha particles. The use of this kind of radiation presents several challenges based upon the attenuation that alpha particles suffer before interaction with biological targets such as DNA. When the mean dose is very low, alpha irradiation leads to a non-homogeneous energy distribution, whereas a small number of biological targets can receive absorbed doses of up to 1 Gy $(17,18)$. Despite these problems, the study of the effects of alpha particles in the low-dose range is essential for determining the RBE, the value assigned to this kind of radiation, and is usually used for risk assessment for people exposed to radiation (19).

The aim of the present work was to study whether low doses of alpha particles due to radon modulate the expression of genes related to apoptosis at a transcriptional level.

\section{Materials and methods}

Cell cultures and alpha particle irradiation. The effects of alpha particles on cancer cells were studied with the stable MCF-7 line of human breast cancer cells, purchased from the American Type Collection (Rockville, MD, USA). The cells were maintained as a monolayer culture in $75-\mathrm{cm}^{2}$ culture flasks in Dulbecco's modified Eagle's medium (DMEM) supplemented with $5 \%$ fetal bovine serum (FBS), penicillin (20 units $/ \mathrm{ml}$ ) and streptomycin $(20 \mu \mathrm{g} / \mathrm{ml})$, at $37^{\circ} \mathrm{C}$ in a humid atmosphere containing $5 \% \mathrm{CO}_{2}$. Cells were subcultured every 3-4 days by suspension in $5 \mathrm{mM} \mathrm{Na}_{2}$-EDTA in PBS (pH 7.4) at $37^{\circ} \mathrm{C}$ for $5 \mathrm{~min}$.

Before the experiment, cells from stock subconfluent monolayers $(80 \%)$ of MCF-7 were incubated with $5 \mathrm{mM}$ $\mathrm{Na}_{2}$-EDTA in PBS ( $\mathrm{pH} \mathrm{7.4)}$ ) at $37^{\circ} \mathrm{C}$ for $5 \mathrm{~min}$, resuspended in DMEM supplemented with 5\% FBS and passed repeatedly through a 25 -gauge needle to produce a single cell suspension. Cell counts and viability were determined by staining a small volume of cell suspension with $0.4 \%$ trypan blue saline solution and examining the cells in a hemocytometer. MCF-7 cells $\left(3 \times 10^{5}\right.$ cells/dish) were seeded onto $60 \times 15-\mathrm{mm}$ tissue culture dishes in DMEM supplemented with $5 \%$ FBS, penicillin (20 units $/ \mathrm{ml})$ and streptomycin $(20 \mu \mathrm{g} / \mathrm{ml})$. After the cells were firmly attached to the dishes $(4 \mathrm{~h})$, the culture media were aspirated and the plates were refilled with fresh media with different radon concentrations.

Cell irradiation with alpha particles was due to the presence of ${ }^{222} \mathrm{Rn}$ and its short-life daughters, previously dissolved in culture medium, as described previously (20). The radoncontaining culture medium was obtained by dissolving the gas from a liquid radium $\left({ }^{226} \mathrm{Ra}\right)$ sample. The radon produced by the radium sample diffused through the air in a closed system, and was dissolved in the culture medium in a sterile vial (Fig. 1). The concentration of radon in the culture medium depends on the time the gas has been diffusing from the source. After different times of exposure to radium, the vials were tightly closed and the radon concentration was measured

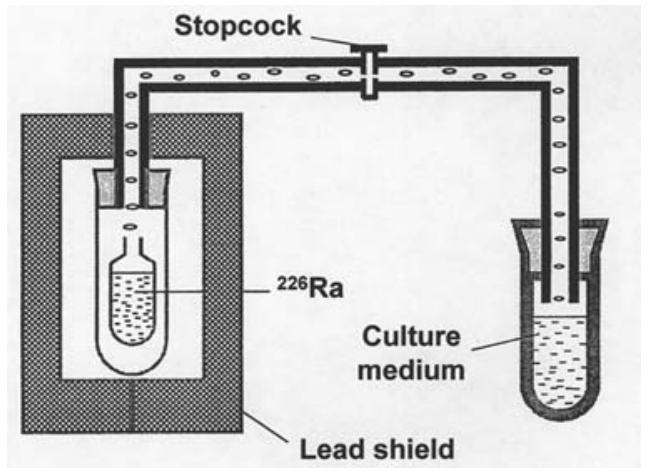

Figure 1. Experimental setup for dissolution of radon in cell culture medium.

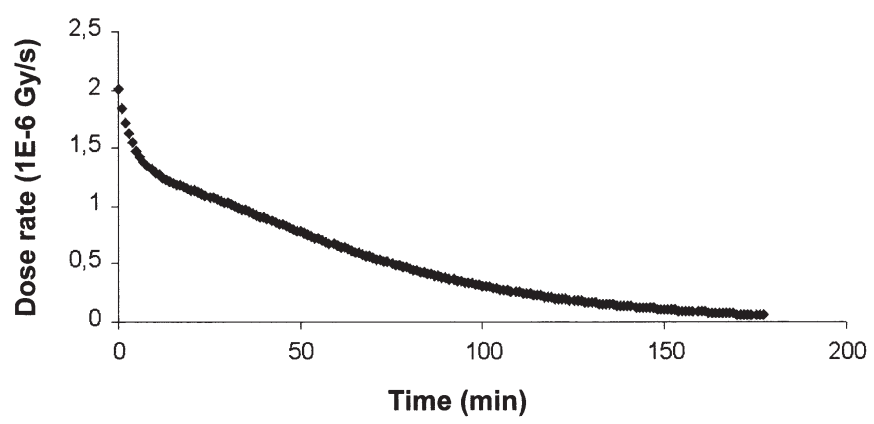

Figure 2. Dose rate evolution within cell cultures under the experimental conditions used.

using a gamma spectrometry semi-conductor GeHP (Canberra) coupled to a multichannel analyser. The short-life radon daughter gamma emitters were determined under the $352 \mathrm{keV}$ ${ }^{214} \mathrm{~Pb}$ and $612 \mathrm{keV}{ }^{214} \mathrm{Bi}$ photopeaks. This assumption can only be made under radioactive equilibrium conditions. Successive measurements showed a progressive radioactive equilibrium between radon and its daughters, and a plateau was reached after $3 \mathrm{~h}$.

The culture media were heated to $37^{\circ} \mathrm{C}$ in the same sealed vials. They were then filtered and added to the plates. MCF-7 cells were incubated for 3 days in either radon containing or control culture media. After this, the cells were harvested by treatment with a $0.25 \%$ trypsin-phosphate-buffered saline solution, passed through a 25 -gauge sterile needle several times and counted using a hemocytometer. We performed six experiments and, in each experiment, four irradiated plates and four control plates (unirradiated) were used for each alpha dose.

In each case, the dose absorbed by the cell cultures was calculated from the initial radon concentration in radioactive equilibrium with its descendants. Considering the diffusion of radon gas from the culture medium to the air, the total absorbed doses in cell cultures can be calculated from the initial populations of each isotope as well as their alpha energy of emission (6.00 MeV-218 $\mathrm{Po}$ and $7.68 \mathrm{MeV}-{ }^{214} \mathrm{Po}$ ). The calculated doses for the cells in the six experiments were 0.6 , 1.2, 1.6, 2.4, 5.1 and $8.3 \mathrm{mGy}$. Fig. 2 shows the relationship between dose rate and time. It can be observed that the dose rate is not constant during the irradiation period but fluctuates in the same way as the alpha energy emitted by a mixture of 


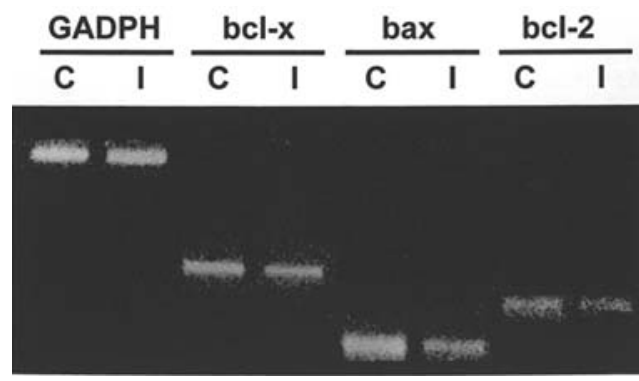

Figure 3. Agarose gel electrophoresis showing expression of the genes studied in control cells (C) and irradiated cells (I).

radon daughters initially in equilibrium. Because of the absence of radon, the dose rate reaches zero after $200 \mathrm{~min}$, the decrease curve being a combination of ${ }^{218} \mathrm{Po}$ and ${ }^{214} \mathrm{Po}$ decay curves.

RNA extraction and RT-PCR assays. After cell counting, RNA was extracted from each radon-containing plate as previously described (21). Total RNA samples were treated with RNAsefree DNAse I (Pharmacia) to remove any contaminating genomic DNA, quantified by spectrophotometry, diluted as appropriate to equalize and stored at $-70^{\circ} \mathrm{C}$ until use. Differences in relative mRNA levels of bcl- 2 , bcl- $x_{L}$ and bax genes among irradiated and non-irradiated MCF-7 cells were assessed by analysis of semi-quantitative reverse transcriptase-polymerase chain reaction (RT-PCR) method. Briefly, $1 \mu \mathrm{g}$ of total cellular RNA was reverse-transcribed at $42^{\circ} \mathrm{C}$ for $1 \mathrm{~h}$ in a reaction containing $10 \mathrm{mM}$ Tris- $\mathrm{HCl} \mathrm{pH} 7.6,12 \mathrm{mM} \mathrm{KCl}$, $2 \mathrm{mM} \mathrm{MgCl}_{2}, 200 \mu \mathrm{M}$ dNTPs, $0.5 \mu \mathrm{M}$ random hexamers, 40 units RNasin (Promega, Madison, WI) and 200 units avian myeloblastosis virus reverse transcriptase (Gibco-BRL) in a final volume of $40 \mu 1$.

As a control, the constitutively expressed GAPDH gene, the mRNA levels of which were not modified by the alpha particle doses used in the study, was evaluated in addition to the apoptosis genes in each sample. Ten percent of the cDNA product was then subjected to a polymerase chain reaction containing $10 \mathrm{mM}$ Tris- $\mathrm{HCl} \mathrm{pH} 8.3,50 \mathrm{mM} \mathrm{KCl}, 0.001 \%$ (w/v) gelatin, $2 \mathrm{mM} \mathrm{MgCl}, 200 \mu \mathrm{M}$ dNTPs, and 1 unit Taq polymerase (BioTaq, BioLine) using the appropriate pair of primers $(0.5 \mu \mathrm{M}$ each $)$ with the following reaction temperature pattern: $94^{\circ} \mathrm{C}$ for $5 \mathrm{~min}$; twenty-five cycles of $94^{\circ} \mathrm{C}$ for $30 \mathrm{sec}$, $60^{\circ} \mathrm{C}$ for $30 \mathrm{sec}$, and $72^{\circ} \mathrm{C}$ for $1 \mathrm{~min}$; and $72^{\circ} \mathrm{C}$ for $5 \mathrm{~min}$. PCR was performed in a total volume of $50 \mu 1$ using a thermocycler (GenAmpPCR system2400, Perkin Elmer).

For amplification of bcl-2, bcl-x and bax genes, the following primers (5'-3') were used: 5' primer AGATGTCCA GCCAGCTGCACCTGAC and 3' primer AGATAGGCA CCAGGGTGAGCAAGCT for the $b c l-2$ gene, 5' primer CG GGCATTCAGTGACCTGAC and 3' primer TCAGGAACC AGCGGTTGAAG for the $b c l$-x gene, $5^{\prime}$ primer ATGGACG GGTCCGGGGAGCAGC and 3' primer CATCCTGAGGCA CCGGGTCC for the bax gene, and 5' primer GGTCTTACT CCTTGGAGGCCATGTG and 3' primer ACCTCACTACA TGGTTTACATGTT for the GAPDH gene.

In these conditions, PCR amplification curves using multiple numbers of cycles revealed that 25-27 cycles were optimal for semi-quantitative amplification of the bcl-2, bcl- $x_{\mathrm{L}}$

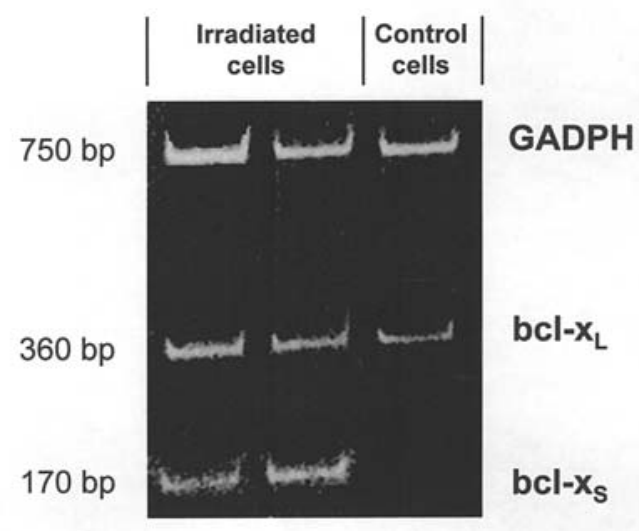

Figure 4. Expression of bcl-x mRNA levels after alpha particle irradiation doses.

and bax gene fragments. PCR products were visualised after conventional electrophoresis through $2 \%$ agarose gels or through 4-20\% polyacrylamide gel (NOVEX) at $300 \mathrm{~V}$ and a constant temperature of $12^{\circ} \mathrm{C}$, both by staining with ethidium bromide. The specificity of the PCR product was verified by direct sequencing of the DNA extracted from gels in an ABI-310 sequencer using AmpliTaq Gold polymerase and a dye terminators cycle sequencing kit (Applied Biosystem). Sequences of oligonucleotides used for sequencing were the same as those used for PCR amplification. The annealing temperature for all primers was $60^{\circ} \mathrm{C}$.

\section{Results}

As expected, the cell count after 3 days in the incubation chamber showed less growth in the irradiated populations than in the controls. No dose-dependent growth was observed within the narrow range of doses studied. The irradiated cell populations reached an average of $85 \%$ of the value for nonirradiated cells, with a statistically significant difference between the two experimental groups.

Standard RT-PCR (number of cycles to saturation) showed that the MCF-7 breast cancer cell line expresses the Bcl-2 family apoptosis-related genes, bcl-2, bax, and bcl-x, at high levels. As a result of low-dose alpha irradiation, by means of semi-quantitative RT-PCR performed under non-saturated conditions ( 25 cycles), slight differences were observed in the mRNA levels of the Bcl-2 family genes studied. Both bax and $b c l-2$ were underexpressed in the irradiated cells when compared with controls, but it was difficult to establish any variation in the expression of $b c l$-x (Fig. 3).

Refined semi-quantitative analysis for $b c l-\mathrm{x}_{\mathrm{L}}$ was performed in electrophoreses in a gradient polyacrylamide gel of high resolution. Fig. 4 shows simultaneous GAPDH and $b c l$-x PCRproduct electrophoreses, from control cells and cells irradiated with alpha particle doses from 0.6 to $8.3 \mathrm{mGy}$. In reference to GADPH, the apoptosis inhibiting long transcript bcl- $\mathrm{x}_{\mathrm{L}}$ was significantly overexpressed in cells irradiated with doses over $10^{-3} \mathrm{~Gy}$. In these cases, but not in the control cells, the apoptosis inducing short transcript, bcl- $\mathrm{x}_{\mathrm{S}}$, was also expressed. Table I shows a semi-quantitative summary of the results concerning the expression of the studied genes. 
Table I. Semi-quantitative summary of mean expression levels in studied genes.

\begin{tabular}{lcc}
\hline Genes & Control cells & Irradiated cells \\
\hline GADPH & ++++ & ++++ \\
bcl- $x_{S}$ & - & $+/++$ \\
bcl- $x_{\mathrm{L}}$ & ++ & +++ \\
bcl-2 & ++ & + \\
bax & ++++ & ++ \\
\hline
\end{tabular}

In the irradiated cells, but not in control cells, a band $190 \mathrm{bp}$ smaller than that corresponding to $b c l$ - $\mathrm{x}_{\mathrm{L}}$ was observed (Fig. 4). Differentially expressed bands were then excised from the electrophoresis gel and analysed by direct sequencing using the primers designed for bcl- $\mathrm{x}_{\mathrm{L}}$ analysis. The results showed that larger fragments (360 bp) corresponded, as expected, to a bcl- $x_{\mathrm{L}}$ fragment, and the sequence from the smaller band (170 bp) corresponded to the apoptosis-inducing bcl- $\mathrm{x}_{\mathrm{S}}$ form (Fig. 5).

\section{Discussion}

The use of radiation to increase the efficacy of a chemotherapeutic agent in the treatment of cancer patients is an interesting possibility because of the need to reduce both the action on healthy cells and side effects $(1,2)$. The aim of this treatment modality is for the radiation to produce a sublethal effect on the cells, which makes them more sensitive to the action of the drug and thus increases its efficacy. In vitro low doses of alpha particle irradiation due to radon have an antiproliferative effect on the growth of MCF-7 cells. The application of low doses of radiation due to radon increases the sensibility of the cancer cells to taxol, and cells exposed first to low doses of radon and then to a concentration of $50 \mathrm{nM}$ of taxol therefore exhibit a lower proliferation rate and a lower viability than cells treated with taxol but not irradiated (5). Taxol is a chemotherapeutic agent that is mainly used to treat ovarian and breast cancer and is given to patients in the metastatic phase. Its mode of action seems to be related to the stabilization of the structure of the microtubules, preventing these from acting as a mitotic spindle and stopping cell division in the $\mathrm{M}$ phase of the cell cycle. The loss of the capacity to divide leads to cellular apoptosis through increased expression of p53 or by inactivation of bcl-2 (22). Because both taxol and low radon doses seem to affect the proliferation of MCF-7 cells and taxol modifies the expression of apoptosis-related genes, we considered it of interest to study whether low doses of alpha particle irradiation from radon gas modify the expression of some Bcl-2 family apoptosis-related genes (bax, bcl-2 and bcl-x) in MCF-7 human breast cancer cells.

The present study demonstrates that irradiation with low radon doses of MCF-7 cells induces underexpression of both bax and bcl-2 genes. Interestingly, the mRNA levels of the full-length bcl-x gene $\left(b c l-x_{L}\right)$ were overexpressed after irradiation, and significant mRNA levels of an alternative mRNA splicing form of the same gene $\left(\mathrm{bcl}-\mathrm{x}_{\mathrm{S}}\right)$ were detected, as reported in the literature (14), which enhances the apoptotic sensitivity of the cell.

Bcl-2 overexpression is capable of inhibiting cell death in response to many disparate apoptotic signals, whereas bax belongs to the pro-apoptotic family members. The bcl-x gene encodes at least two protein products, differentiated by alternative mRNA splicing, which have opposite effects on

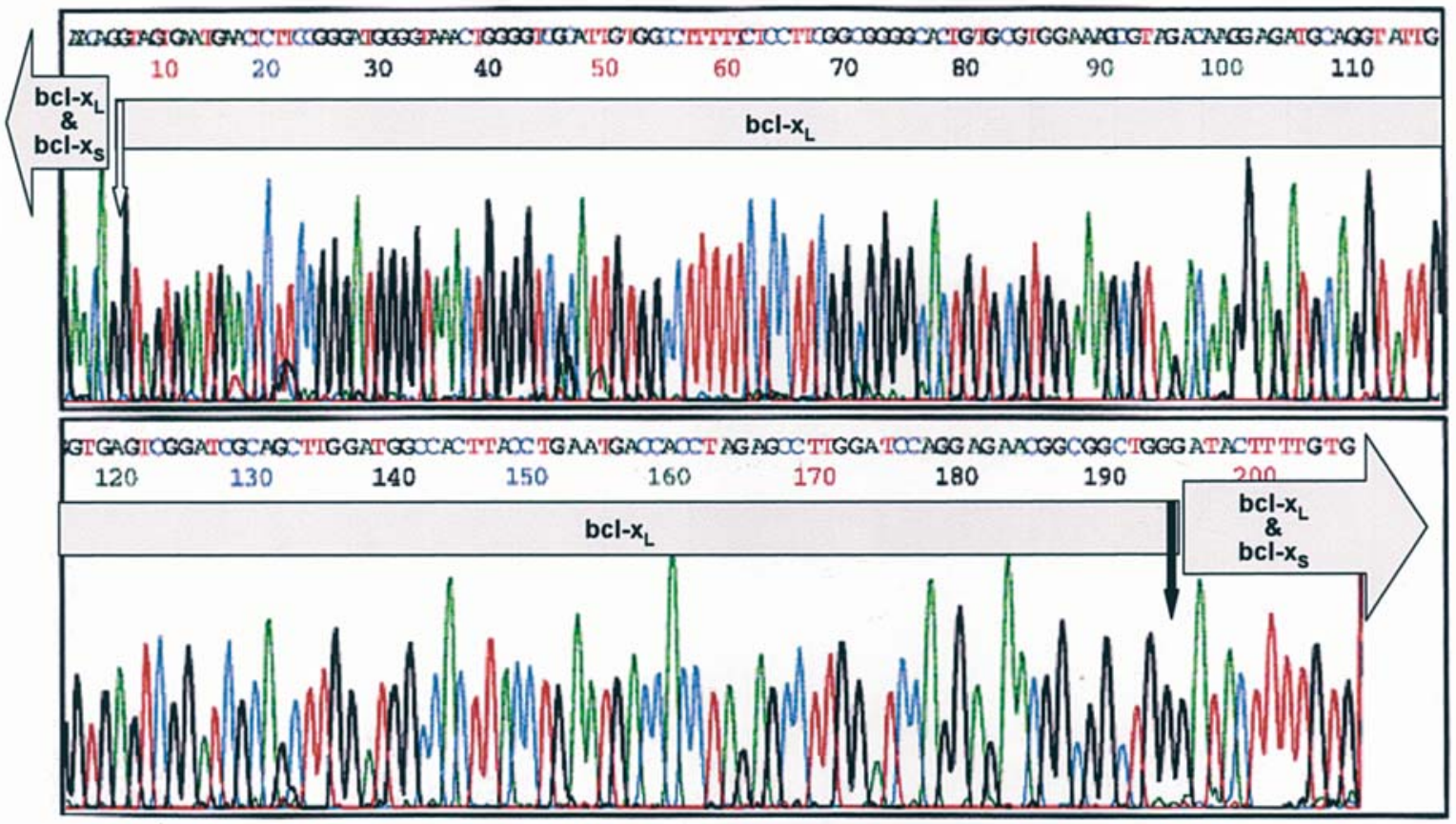

Figure 5. Part of the 370-bp PCR product sequence corresponding to bcl- $\mathrm{x}_{\mathrm{L}}$, including the sequence absent in bcl- $\mathrm{x}_{\mathrm{S}}$ (170-bp PCR product). Splice junctions of the two alternative $5^{\prime}$ splice sites are annotated to be AGgtagtg ( 5 ' splice site for bcl- $\mathrm{x}_{\mathrm{S}}$, lower case letters representing the intron sequence - white arrow) and GGgtaaga (5' splice site for bcl- $\mathrm{x}_{\mathrm{L}}$ - black arrow). 
apoptotic induction. Full-length bcl- $\mathrm{x}_{\mathrm{L}}$ is homologous to bcl2 and has a similar ability to inhibit cell death by multiple pathways. The truncated bcl- $\mathrm{x}_{\mathrm{S}}$ protein is able to inhibit the action of either bcl-2 or bcl- $x_{L}$, and enhances the apoptotic sensitivity of the cell.

Despite the different source of alpha radiation, the effects observed in our study can be compared with those found with ${ }^{239} \mathrm{Pu}$ sources. A representative example of the studies performed with this type of irradiation is the study by Kadhim et al (23), who made interesting observations concerning the number of cells that suffer direct interactions with alpha particles, which was similar to that found by Mays et al (24). These studies suggest that, for low radiation doses, the percentage of cells affected by alpha particles is small and the effects observed are mainly indirect, due to the creation of chemical species in the culture medium and to the further action of these on DNA or, more frequently, on RNA. Radiation-induced gene expression in MCF-7 cells has been recently described and, simultaneously, both the inhibition of cell proliferation and that of other cellular functions (e.g. cell repair) have been found (25).

The changes in the splicing sites that were detected in the bcl-x gene following irradiation would seem to confirm the indirect effect. $\mathrm{Bcl}-\mathrm{x}_{\mathrm{S}}$ transcript formation results from these cuts produced by radiation in two specific loci of the mRNA chain. By aligning the human bcl- $\mathrm{x}_{\mathrm{L}}$ and bcl- $\mathrm{x}_{\mathrm{S}} \mathrm{cDNA}$ with the bcl-x genomic from GenBank (8), the splice junctions of the alternative $5^{\prime}$ splice sites are annotated to be AGgtagtg (5' splice site for bcl- $\mathrm{x}_{\mathrm{S}}$, lower case letters representing the intron sequence) and GGgtaaga (5' splice site for bcl- $\mathrm{x}_{\mathrm{L}}$ ) (26) (Fig. 5). Considering the stochastic character of energy depositions due to radiation, the induced lesions appear to be a consequence of a chemical interaction at all points of the mRNA molecule, with breakage occurring at the weakest. In the study by Kadhim et al (23), the effect of alpha irradiation is manifested as a chromosomal instability that is transmitted to the progeny of the irradiated hematopoietic cells. This chromosomal instability and the resulting increased mutagenicity would seem to be paralleled by the increased expression of bcl- $\mathrm{x}_{\mathrm{L}}$ found in our study. Since irradiation with alpha particles increases expression of bcl- $\mathrm{x}_{\mathrm{L}}$, it results in decreased apoptosis and elimination of cells with a high degree of mutation, thereby increasing the possibility of mutagenesis.

However, the increased sensitivity to apoptosis resulting from bcl- $\mathrm{x}_{\mathrm{S}}$ overexpression is important because it might improve the efficacy of chemotherapeutic agents in the treatment of cancer. The study by Sumantran et al (11) showed that the chemotherapeutic agent, taxol, was more effective if MCF-7 tumor cells had been previously treated to induce bcl- $\mathrm{x}_{\mathrm{S}}$ expression by means of an adenovirus vector. Our finding that low radiation doses of alpha particles induce $b c l-x_{S}$ expression opens up the possibility for application of this naturally occurring agent for the same purpose.

\section{References}

1. Rosenthal DI and Carbone DP: Taxol plus radiation for head and neck cancer. J Infus Chem 5: 46-54, 1995.

2. Vokes EE and Weichselbaum RR: Concomitant chemoradiotherapy: rationale and clinical experience in patients with solid tumors. J Clin Oncol 8: 911-934, 1990.
3. Kharazi AI, James SJ, Taylor JMG, Lubinski JM, Nakamura LT and Makinodan T: Combined chronic low dose radiation-caloric restriction: a model for regression of spontaneous mammary tumor. Int J Radiat Oncol Biol Phys 28: 641-647, 1994.

4. Soto J, Quindós LS, Cos S and Sánchez-Barceló EJ: Influence of low doses of radiation due to ${ }^{222} \mathrm{Rn}$ on proliferation of fibroblasts and MCF-7 human breast cancer cells in vitro. Sci Total Environ 181: 181-185, 1996.

5. Soto J, Sáinz C, González-Lamuño D, Falkenbach A and Cos S: Low radon doses sensitize MCF-7 human breast cancer cells to taxol. Oncol Rep 7: 941-944, 2000.

6. Korsmeyer S: Bcl-2 initiates a new category of oncogenes: regulators of cell death. Blood 80: 879-887, 1992.

7. Minn A, Rudin C, Boise L and Thompson C: Expression of bcl- $\mathrm{x}_{\mathrm{L}}$ can confer a multidrug resistance phenotype. Blood 86: 1903-1910, 1995.

8. Boise L, Gonzalez-Garcia M, Postema C, Ding L, Lindsten T, Turke L, Mao X, Nuñez G and Thompson C: Bcl-x, a bcl-2 related gene that functions as a dominant regulator of apoptosis cell death. Cell 74: 597-608, 1993.

9. Oltvai Z, Milliman C and Korsmeyer S: Bcl-2 heterodimerizes in vivo with a conserved homolog, bax, that accelerates programmed cell death. Cell 74: 609-619, 1993.

10. Zhan Q, Alamo I, Yu K, Boise L, Cherney B, Tosato G, O'Connor $\mathrm{P}$ and Fornace A: The apoptosis associated gammaray response of bcl- $\mathrm{x}_{\mathrm{L}}$ depends on normal p53 function. Oncogene 13: 2287-2293, 1996 .

11. Sumantran VN, Eslovega MW, Nuñez G, Clarke MF and Wicha MS: Overexpression of bcl- $\mathrm{x}_{\mathrm{S}}$ sensitizes cells to chemotherapy-induced apoptosis. Cancer Res 55: 2507-2510, 1995.

12. Wang B, Takeda H, Gao W, Zhou K, Odaka T, Ohyama H, Yamada $\mathrm{T}$ and Hayata I: Induction of apoptosis by beta radiation from tritium compounds in mouse embryonic brain cells. Health Phys 77: 16-23, 1999.

13. Ducau J, Breglians J and Saint-André C: Gamma irradiation stimulates homology directed DNA double strand break repair in Drosophila embryo. Mutat Res 460: 69-80, 2000.

14. Lorimore S, Kadhim M, Pocock D, Papworth D, Steves D, Goodhead D and Wright E: Chromosomal instability in the descendants of unirradiated surviving cells after alpha particle irradiation. Proc Natl Acad Sci USA 10: 5710-5733, 1998.

15. Pohl-Ruling J, Lettner H, Hoffmann W, Eckl P, Haas O and Obe G: Chromosomal aberrations of blood lymphocytes induced in vitro by radon 222 daughter alpha irradiation. Mutat Res 449: $7-19,2000$.

16. Georgakilas A, Haveles K, Sophianopoulou V, Sakellion L, Zarris G and Sideris E: Alpha particle induced changes in the stability and size of DNA. Radiat Res 153: 258-262, 2000.

17. United Nations Scientific Committee on the effects of Atomic Radiation: Sources and Effects of Ionizing Radiation. UNSCEAR 2000 Report to the General Assembly with Annexes, New York. Volume II: Effects. United Nations Publication, Sales No. E.00.IX.4, New York, 2000.

18. Goodhead D: Spatial and temporal distribution of energy. Health Phys 55: 231-240, 1988.

19. Baverstock K and Thorne M: An illustrative comparison of the event-size distribution for gamma-rays and alpha particles in the whole mammalian cell nucleus. Int J Radiat Biol 74: 799-804, 1998.

20. Soto J, Sáinz C, Cos S and González-Lamuño D: A simple method of alpha irradiation for experiments in radiobiology. Nucl Instr Meth Phys Res B 197: 310-316, 2002.

21. Chomzcynsky P and Sacchi N: Single step method of RNA isolation by and guanidinium thiocyanate-phenol-chloroform extraction. Anal Biochem 162: 156-159, 1987.

22. Holmes FA, Walkers RS, Theriault RL, Forman AD, Newton LK, Raber MN, Buzdar AV, Frue D and Hortobagyi GN: Phase II trial of taxol, an active drug in the treatment of metastasic breast cancer. J Natl Cancer Inst 83: 1797-1805, 1991.

23. Kadhim M, MacDonald D, Goodhead D, Lorimore S, Marsden S and Wright E: Transmission of chromosomal instability after plutonium alpha particle irradiation. Nature 355: 738-740, 1992.

24. Mays C, Lloyd R and Wrenn T: Cancer incidence and lifespan vs alpha particle dose in beagles. Health Phys 52: 617-624, 1987.

25. Stassen T, Port M, Nuyken I and Abend M: Radiation-induced gene expression in MCF-7 cells. Int J Radiat Biol 79: 319-331, 2003.

26. Burge CB, Padgett RA and Sharp PA: Evolutionary fates and origins of U12-type introns. Mol Cell 2: 773-785, 1998. 